\title{
Manajemen Panen Kelapa Sawit (Elaeis guineensis Jacq.) di Sungai Bahaur Estate, Kotawaringin Timur, Kalimantan Tengah.
}

\section{Havest Management of Oil Palm (Elaeis guineensis Jacq.) at Sungai Bahaur Estate, Kotawaringin Timur, Central Kalimantan}

\author{
Saut Mangasi Hutabarat dan Heni Purnamawati* \\ Departemen Agronomi dan Hortikultura, Fakultas Pertanian, Institut Pertanian Bogor \\ (Bogor Agricultural University), Jl. Meranti, Kampus IPB Darmaga, Bogor 16680, Indonesia \\ Telp.\& Faks.62-251-8629353 e-mailagronipb@indo.net.id \\ *Penulis untuk korespondensi: heni_purnama@yahoo.com
}

Disetujui 18 Januari 2016/ Published online 25 Januari 2016

\begin{abstract}
The aims of this internship is to identify and understand the specific management of harvesting oil palm plantations. The author can make observations include the calculation of the density of the harvest, the harvest energy needs, the quality of the harvest work, violations and penalties harvest, harvest criteria and the quality of the harvest area. Observations indicate harvesting management less well in the SBHEfield. The results showed the number of labor in the field is higher than the harvest labor requirements. The quality of the harvest work in field is still substandard. Harvesters cut less mature fruit is higher than the standard tolerance field and harvesting of ripe fruits was lower by $79 \%$ than the standard minimum of the garden that is $85 \%$. The need for supervision harvesting and giving understanding to the harvester so that the quality in accordance with company standards. Penalties can increase the sense of responsibility of harvesting on their area.
\end{abstract}

Keyword: fruit bunch, harvest density, harvest labor

\begin{abstract}
ABSTRAK
Magang bertujuan untuk mengetahui dan memahami secara khusus manajemen pemanenan perkebunan kelapa sawit. Pengamatan yang dilakukan meliputi perhitungan angka kerapatan panen, kebutuhan tenaga panen, kualitas pekerjaan panen, pelanggaran dan denda panen, kriteria panen dan mutu hanca panen. Hasil pengamatan menunjukkan manajemen pemanenan di kebun SBHE kurang baik. Hasil pengamatan menunjukkan jumlah tenaga kerja di lapangan lebih tinggi dari kebutuhan tenaga kerja panen. Kualitas pekerjaan panen masih di bawah standar kebun. Pemanen memotong buah kurang matang lebih tinggi dari toleransi standar kebun dan pemanen memotong buah matang lebih rendah yaitu $79 \%$ dari standar minimal kebun yaitu $85 \%$. Perlu adanya pengawasan pemanenan dan pemberian pemahaman kepada pemanen sehingga kualitas sesuai dengan standar perusahaan. Pemberlakuan denda dapat meningkatkan rasa tanggung jawab pemanen terhadap hancaknya.
\end{abstract}

Kata kunci : brondolan, kerapatan panen, tenaga kerja panen 


\section{PENDAHULUAN}

Sub sektor perkebunan merupakan andalan pembangunan pertanian Indonesia. Komoditas perkebunan di Indonesia dapat meningkatkan taraf hidup petani, menambah devisa negara, menciptakan lapangan pekerjaan, dan melestarikan sumber daya alam. Kelapa sawit merupakan salah satu komoditi perkebunan. Produk kelapa sawit dapat digunakan sebagai minyak goreng, bahan kosmetika dan farmasi serta bahan non makanan (sabun, deterjen, tinta cetak) (Mangoensoekarjo dan Semangun, 2003).

Kebutuhan minyak nabati dan lemak dunia terus meningkat sebagai akibat pertumbuhan penduduk (Pahan, 2007). Kelapa sawit disebut sumber minyak nabati utama karena tanaman kelapa sawit merupakan sosok tanaman yang cukup tangguh, terutama bila terjadi perubahan musim. Minyak kelapa sawit memiliki keunggulan dibandingkan dengan minyak nabati lainnya, yaitu tingkat efisiensi minyak sawit tinggi sehingga mampu menempatkan CPO menjadi sumber minyak nabati termurah, penggunaannya sangat luas, diantaranya minyak goreng dan margarin, produktivitas minyak sawit tinggi yaitu 3.2 ton $\mathrm{ha}^{-1}$. Oleh karena itu, perlu dilakukan usaha untuk meningkatkan produktivitas kelapa sawit.

Panen adalah kegiatan memotong buah masak, memungut brondolan dan sistem pengangkutannya dari pokok ke tempat pengumpulan hasil (TPH) hingga ke pabrik. Manajemen panen dan pengolahan hasil merupakan rangkaian terakhir dari kegiatan budi daya kelapa sawit di lapangan yang berkaitan dengan kualitas minyak sawit. Oleh karena itu, pengelolaan panen yang baik harus dilakukan untuk mendapatkan produksi dengan kualitas dan kuantitas yang baik pula. Faktor-faktor yang menentukan keberhasilan pemanenan adalah persiapan panen, kriteria matang panen, angka kerapatan panen, sistem, dan rotasi panen, ramalan produksi, kebutuhan tenaga kerja dan angkutan panen, basis,dan premi panen (Lubis, 2008).

Persiapan panen, pemanenan dan penentuan jumlah tenaga kerja panen hingga pengangkutan tandan buah segar ke pabrik menjadi hal penting yang harus diperhatikan karena berhubungan dengan pencapaian produktivitas dan tingkat rendemen minyak yang berkualitas serta mengurangi kehilangan produksi panen. Salah satu sumber kehilangan hasil adalah terdapat buah mentah yang terpanen, buah masak tinggal di pokok (tidak dipanen), brondolan tidak dikutip, buah busuk, dan buah abnormal.
Berdasarkan Direktorat Jenderal Perkebunan (2014) ekspor minyak kelapa sawit (palm oil) mengalami peningkatan baik volume maupun nilainya. Nilai ekspor kelapa sawit meningkat pada tiga tahun terakhir yaitu: tahun 2011 sebesar 16436202 ton, tahun 2012 sebesar 18850836 ton, dan tahun 2013 mencapai 20577 967 ton. Nilai tersebut setara dengan US\$ 15838 850. Tujuan dari kegiatan magang secara umum yaitu meningkatkan kemampuan, menambah pengalaman, dan memperluas wawasan bagi mahasiswa dalam proses kerja secara nyata. Tujuan khusus dari kegiatan magang ini adalah untuk mempelajari pemanenan secara teknis maupun pengelolaan.

\section{BAHAN DAN METODE}

Kegiatan magang dilaksanakan selama empat bulan dimulai dari tanggal 11 Februari sampai 11 Juni 2013. Magang berlokasi di Sungai Bahaur Estate (SBHE), Desa Pundu, Kecamatan Cempaga Hulu, Kabupaten Kotawaringin Timur, Kalimantan Tengah.

Metode yang dilakukan adalah kerja praktik langsung di kebun. Kegiatan yang dilakukan adalah seluruh jenis pekerjaan di lapangan dan dikantor pada seluruh level manajerial yang diijinkan mulai dari karyawan harian lepas (KHL), pendamping mandor, dan pendamping asisten.

Metode yang digunakan pada kegiatan magang adalah metode langsung dan tidak langsung. Metode langsung yang dilakukan adalah praktek kerja langsung di lapangan dengan turut aktif dalam pelaksanaan kegiatan kebun, wawancara, dan diskusi dengan mandor maupun dengan para staf. Metode tidak langsung dilakukan melalui studi dokumentasi kebun (arsip kebun, laporan bulanan, dan laporan tahunan).

Pengumpulan data dan informasi dengan mengumpulkan data primer dan data sekunder. Data sekunder yang diperoleh dari kebun meliputi lokasi kebun, luas areal, kondisi iklim, kondisi lahan, produktivitas, struktur organisasi perusahaan, rekomendasi pelaksanaan teknis budi daya dan informasi-informasi penting lainnya yang dibutuhkan. Data ini diperoleh melalui arsip, informasi dari kantor dan studi literatur.

Pengumpulan data primer dilakukan melalui pengamatan lapangan terhadap semua kegiatan yang berlangsung di perkebunan.Data pengamatan lapangan dipusatkan pada perencanaan kegiatan panen yaitu perhitungan angka kerapatan panen (AKP), kebutuhan tenaga panen, kualitas pekerjaan panen, pelanggaran dan 
denda panen, kriteria panen, dan mutu hanca dan kehilangan produksi.

Peubah yang diamati pada kegiatan magang dengan aspek perencanaan panen tanaman kelapa sawit adalah sebagai berikut:

1. Perhitungan Angka Kerapatan Panen (AKP) dan taksasi produksi

Pengamatan dilakukan pada blok contoh yang akan dipanen keesokan hari dan diamati sebanyak 3 kali. Pengambilan contoh dilakukan dengan mengambil $2.5 \%$ tanaman dari populasi/blok. Metode dalam memilih tanaman contoh adalah dengan mengambil tanaman di beberapa pasar di tepi kanan blok, di tengah blok, dan di tepi kiri blok sehingga benar-benar mewakili kondisi blok contoh. Data diperoleh dari jumlah tanaman contoh dan jumlah tandan yang siap dipanen besok. Angka kerapatan panen dapat diperoleh dengan rumus:

$$
\mathrm{KP}=\frac{\Sigma \mathrm{TM}}{\Sigma \mathrm{TC}} \times 100 \%
$$

Keterangan:

$\mathrm{KP}=$ kerapatan panen

$\mathrm{TM}=$ jumlah tandan matang yang diamati

$\mathrm{TC}=$ jumlah tandan contoh yang diamati

Taksasi memilki hubungan dengan AKP karena data taksasi diperoleh dengan mengalikan jumlah tandan per blok contoh yang siap dipanen besok dengan bobot janjang rata-rata (BTR) yang umum sesuai dengan umur tanaman pada blok yang diamati.

2. Kebutuhan Tenaga Panen

Pengamatan terhadap kebutuhan tenaga panen pada satu divisi. Data diperoleh dari data kantordivisi dan wawancara dengan mandor dan asisten kebun.

3. Kualitas Pekerjaan Panen

Pengamatan kualitas pekerjaan panen didapat dengan melakukan pengamatan kualitatif terhadap sepuluh orang pemanen pada suatu kemandoran. Pelaksanaan pengamatan dilakukan dengan mengamati cara pemanenan yang dilakukan kesepuluh tenaga panen terhada 9 pokok panen dalam 2 pasar pikul atau setara 1 ha. Kriteria pengamatan kualitas pekerjaan panen meliputi : panen semua TBS masak, peletakan TBS di piringan, potong rapat gagang TBS, Buah mentah tidak ditinggal/diperam, antrian TBS teratur di TPH, pengutipan semua brondolan, tumpukan brondolan sendiri, dan tumpukan pelepah bukan di pasar rintis.
4. Pelanggaran dan Denda Panen

Pelanggaran panen di dapat dengan melakukan pengamatan terhadap sepuluh orang pemanen dengan luas hanca panen 1 ha. Pelaksanaan pengamatan dilakukan dengan mengamati 7 kriteria pekerjaan panen meliputi potong buah mentah, brondolan tidak dikutip, brondolan banyak sampah/alas karung, gagang panjang lebih dari $3 \mathrm{~cm}$, pelepah sengkleh, buah busuk, dan over prunning.

5. Kriteria Panen

Pengamatan dilakukan pada 2 kemandoran panen dengan mengikuti 10 pemanen secara acak. Jumlah tandan bertandan matang yang diamati adalah 15 tanaman/pemanen sehingga jumlah keseluruhan 150 tanaman. Pengamatan terhadap tingkat kematangan TBS yang siap dipanen, kriteria diamati berdasarkan jumlah berondolan yang jatuh ke tanah.

6. Mutu Hanca dan Kehilangan Produksi

Pengamatan dilakukan dengan cara mengamati brondolan tertinggal, buah matang tertinggal. Pengamatan dilakukan dengan mengikuti pemanenan secara langsung dan mengamati 5 tenaga panen pada 2 kemandoran.

Data sekunder diperoleh dari laporan pengelolaan (bulanan, triwulan, semesteran, tahunan) yang tersedia di kantor kebun. Data sekunder yang mendukung pelaksanaan teknis panen meliputi lokasi kebun, luas areal, kondisi iklim, kondisi lahan, produktivitas, struktur organisasi perusahaan, rekomendasi pelaksanaan teknis budi daya dan informasi-informasi penting lainnya yang dibutuhkan.

\section{HASIL DAN PEMBAHASAN}

\section{Perhitungan Angka Kerapatan Panen (AKP) dan Taksasi Produksi}

Kegiatan penentuan AKP dinamakan taksasi produksi, kegiatan ini dilakukan sehari sebelum dilaksanakan panen pada blok yang akan dipanen. Tujuan dari penentuan AKP adalah mengetahui banyaknya tandan yang akan dipanen pada hari esok, jumlah pemanen yang diperlukan dan menentukan kebutuhuan jumlah unit transportasi (truk). Pengamatan AKP umumnya dengan mengambil sampel $10 \%$ dari jumlah tanaman yang ada dalam blok.

Penulis melakukan pengamatan terhadap jumlah tandan layak panen pada Blok C008, C009, C010, dan C011 sehari sebelum blok-blok tersebut dipanen pada tanggal 16 Mei 2013. Hasil perhitungan AKP pada keempat blok tersebut dapat dilihat pada Tabel 1. 
Tabel 1. Hasil taksasi harian dan hasil aktual panen kelapa sawit di kebun SBHE

\begin{tabular}{ccccccc}
\hline Blok & $\begin{array}{c}\text { Pokok } \\
\text { diperiksa }\end{array}$ & $\begin{array}{c}\text { Jumlah janjang } \\
\text { matang }\end{array}$ & AKP $(\%)$ & $\begin{array}{c}\text { Estimasi } \\
\text { janjang panen }\end{array}$ & $\begin{array}{c}\text { Jumlah tanaman } \\
\text { produktif }\end{array}$ & $\begin{array}{c}\text { Hasil aktual } \\
\text { janjang panen }\end{array}$ \\
\hline C-008 & 114 & 17 & 14.9 & 576 & 3870 & 521 \\
C-009 & 120 & 20 & 16.6 & 616 & 3712 & 607 \\
C-010 & 105 & 18 & 17 & 664 & 3906 & 687 \\
C-011 & 123 & 26 & 21 & 825 & 3930 & 765 \\
\hline \multicolumn{2}{r}{ Total janjang } & & 2681 & & 2580 & \\
\hline
\end{tabular}

Berdasarkan data di atas terlihat bahwa hasil estimasi jika dibandingkan dengan hasil aktual jumlah janjang hanya memiliki selisih 6 janjang atau $0.26 \%$.Toleransi selisih antara hasil aktual dengan taksasi harian yang berlaku di SBHE adalah 5\%, dengan begitu taksasi yang dilakukan penulis dapat dikatakan sesuai. Perhitungan AKP dan taksasi juga dapat mempengaruhi rotasi panen. Apabila didapatkan hasil perhitungan AKP yang rendah maka akan dilakukan penambahan luas areal panen dari seksi yang lain agar mendapatkan target produksi. Penambahan areal panen akan menyebabkan rotasi panen bertambah cepat.

\section{Kebutuhan Tenaga Kerja}

Kebutuhan tenaga panen untuk satu seksi panen dapat direncanakan tiap harinya berdasarkan pengamatan taksasi buah sehari sebelum blok tersebut akan dipanen. Pengamatan mengenai taksasi harian yang dilakukan penulis dapat dilihat pada Tabel 6, dari hasil pengamatan tersebut dapat diketahui kebutuhan tenaga panen pada seksiB di blok C008, C009, C010, dan C011 yang akan dipanen keesokan harinya. Berikut adalah perhitungan kebutuhan tenaga panen pada seksi B.

Tabel 2. Kebutuhan tenaga kerja panen seksi B

\begin{tabular}{ccccc}
\hline Blok & $\begin{array}{c}\text { Populasi } \\
\text { tanaman }\end{array}$ & $\begin{array}{c}\text { Kerapatan } \\
\text { panen }(\%)\end{array}$ & $\begin{array}{c}\text { Kapasitas } \\
\text { panen } \\
\text { (janjang) }\end{array}$ & $\begin{array}{c}\text { Tenaga } \\
\text { panen } \\
\text { (orang) }\end{array}$ \\
\hline C-008 & 3870 & 14.9 & 110 & 5 \\
C-009 & 3712 & 16.6 & 110 & 6 \\
C-010 & 3906 & 17.0 & 110 & 6 \\
C-011 & 3930 & 21.0 & 110 & 7 \\
\hline
\end{tabular}

Kebutuhan untuk Seksi F adalah 24 orang, namun pada kenyataan lapangan, tenaga pemanen yang dipakai hingga 30 orang tenaga panen. Hal ini menunjukkan bahwa pada divisi tersebut jumlah tenaga panen yang disediakan lebih dari yang dibutuhkan dan kondisi ini dapat menambah biaya produksi yang seharusnya dapat ditekan dengan mengurangi jumlah tenaga pemanen. Pada saat low crop perlu dilakukan pengurangan pemanen kurang dari jumlah pemanen yang dibutuhkan agar tiap pemanen dapat mencapai basis sehingga mendapatkan premi basis panen. Premi basis panen yang didapat bermanfaat untuk meningkatkan kesejahteraan hidup tenaga panen sehingga tenaga panen memiliki loyalitas terhadap perusahaan. Tenaga panen yang digunakan juga tergantung kategori musim panen. Pada saat low crop kondisi panen normal tenaga kerja yang digunakan kurang dari 23 tenaga panen, sedangkan saat peak crop digunakan tenaga panen yang lebih banyak. Jumlah tenaga kerja panen di lapangan juga perlu mempertimbangkan penyebaran kebutuhan dalam setahun.

\section{Kualitas pekerjaan Panen}

Penulis telah melakukan pengamatan kualitatif terhadap sepuluh orang pemanen pada satu kemandoran di Divisi III. Pelaksanaan pengamatan dilakukan dengan mengamati cara pemanenan yang dilakukan kesepuluh tenaga panen terhadap 9 pokok panen dalam 2 pasar pikul atau setara 1 ha. Hasil pengamatan kualitas pekerjaan panen dapat dilihat pada Tabel 3 .

Tabel 3. Kualitas Pekerjaan Potong Buah

\begin{tabular}{clc}
\hline No & \multicolumn{1}{c}{ Kriteria Pengamatan } & $\begin{array}{c}\text { Tenaga kerja } \\
\text { panen }(\%)\end{array}$ \\
\hline 1 & Panen Semua TBS Masak & 100 \\
2 & Peletakan TBS di Piringan & 100 \\
3 & Potong rapat gagang TBS & 100 \\
4 & Buah mentah tidakdiperam & 100 \\
5 & Antrian TBS teratur di TPH & 100 \\
6 & Pengutipan Semua Brondolan & 20 \\
7 & Tumpukan Brondolan Sendiri & 100 \\
8 & Tumpukan pelepah bukan di pasar rintis & 100 \\
\hline
\end{tabular}

Hasil kriteria tersebut menunjukkan bahwa semua pemanen memenuhi kriteria pengamatan kecuali kriteria pengutipan semua brondolan. Kesepuluh pemanen yang diamati, membuktikan hanya ada $20 \%$ pemanen yang melakukan pengutipan bersih semua brondolan. Para pemanen yang tidak mengutip bersih semua brondolan umumnya hanya meninggalkan 1-5 brondolan dari tiap pokok panen, yang tersangkut di ketiak pelepah, tercecer di piringan, atau pasar pikul. Kurangnya kesadaran pemanen terhadap 
pengutipan bersih brondolan menjadi penyebab masalah tersebut karena pemanen menganggap kehilangan 1-5 brondolan tidak akan menjadi masalah. Berdasarkan standar perusahaan toleransi bagi brondolan tidak dikutip adalah 30 butir ha ${ }^{-1}$. Hasil kualitas pekerjaan terhadap tenaga panen menunjukkan bahwa, brondolan yang tidak dikutip pemanen masih berada di bawah batas maksimum toleransi brondolan tidak dikutip.

\section{Pelanggaran Pemanen dan Denda Panen}

Penulis telah melakukan pengamatan kualitatif terhadap sepuluh orang pemanen dengan luas hanca panen 1 ha. Pelaksanaan pengamatan dilakukan dengan mengamati 7 kriteria pekerjaan panen meliputi: potong buah mentah, brondolan tidak dikutip, brondolan banyak sampah/alas karung, gagang panjang lebih dari $3 \mathrm{~cm}$, pelepah sengkleh, buah busuk, dan over prunning. Hasil pengamatan kualitas pekerjaan panen dapat dilihat pada Tabel 4.

Tabel 4. Pelanggaran pemanen dalam pemenuhan basis panen

\begin{tabular}{clc}
\hline No & \multicolumn{1}{c}{ Kriteria pengamatan } & $\begin{array}{c}\text { Pelanggaran } \\
\text { pemanen }(\%)\end{array}$ \\
\hline 1 & Potong buah mentah & 10 \\
2 & Brondolan tidak dikutip & 80 \\
3 & Brondolan banyak sampah & 20 \\
4 & Ganggang panjang lebih dari $3 \mathrm{~cm}$ & 20 \\
5 & Pelepah sengkleh & 20 \\
6 & Buah busuk & 20 \\
7 & Over pruning & 40 \\
\hline
\end{tabular}

Hasil pengamatan menunjukkan $10 \%$ pemanen melakukan potong buah mentah. Berdasarkan standar perusahaan tidak ada toleransi bagi pemanen untuk melakukan potong buah mentah. Terdapat $80 \%$ pemanen tidak mengutip keseluruhan berondolan di pokok, piringan, pasar pikul, atau TPH dengan sisa 5 brondolan secara rata-rata pada pokok panen dan sedikitnya terdapat rata-rata 1 brondolan pada setiap pokok panen yang tidak dikutip bersih, kemudian dapat dilihat bahwa $20 \%$ yang melakukan kesalahan pekerjaan potong buah mengenai berondolan/alas karung banyak sampah, ganggang panjang lebih dari $3 \mathrm{~cm}$ rata-rata, pelepah sengkleh (bukan sengkleh alami), buah busuk, dan over pruning dilakukan oleh $40 \%$ pemanen pada setiap kriteria kesalahan tersebut dan setidaknya terdapat minimal 1 pokok panen pada setiap pelanggaran pemanenan. Setiap pelanggaran pekerjaan potong buah yang dilakukan oleh tenaga panen akan mendapatkan denda untuk setiap kesalahan yang dilakukan. Ketentuan denda telah diatur oleh perusahaan yang ditetapkan dalam IOM (Intern Office Memo) premi dan sangsi panen. Denda akan langsung diberikan oleh mandor panen. Setiap kesalahan yang dilakukan tenaga panen juga akan berdampak pada mandor panen dan Mandor I. Tenaga panen melakukan kesalahan dalam pekerjaan potong buah karena kurangnya kesadaran atau tanggung jawab dalam pekerjaan. Pencegahan terhadap kesalahan berulang yang dilakukan tenaga panen, dapat dilakukan dengan mengingatkan kewajiban mereka dan kesalahankesalahan pekerjaan potong buah yang tidak boleh dilakukan. Peringatan disampaikan oleh mandor panen pada setiap apel pagi saat tenaga panen akan memulai pekerjaan potong buah.

\section{Kriteria Panen}

Standar kematangan buah adalah ketentuan TBS yang dipanen berdasarkan pada jumlah brondolan lepas. Kriteria matang panen ditentukan pada saat kandungan asam lemak bebas atau free fatty acid (ALB atau FFA) minimal (Fauzi et al., 2002). Kriteria matang panen ditetapkan berdasarkan kebijakan perusahaan yang diterapkan pada pekerjaan potong buah di lapangan dan proses grading di pabrik kelapa sawit.

Secara umum untuk lingkup perusahaan menggunakan 2 kriteria panen yaitu kriteria layak potong dan kriteria matang panen. Kriteria layak potong untuk kondisi potong buah di lapangan sedangkan kriteria matang panen untuk kondisi grading buah di PKS. Pemotongan buah yang dilakukan di lapangan pada saat 5 berondolan jatuh alami di piringan, saat di PKS menunjukkan hasil mutu buah mentah $0 \%$, kurang matang $<8 \%$, matang $85 \%$, lewat matang $<7 \%$, dan janjang kosong 0\% sesuai dengan kriteria matang PKS yang menggunakan 2 brondolan $\mathrm{kg}^{-1}$. Hal ini terjadi karena diestimasikan dalam pengangkutan buah, mulai dari saat buah dipotong di lapangan hingga buah tiba di PKS jumlah brondolan akan bertambah sehingga buah akan memenuhi kriteria matang panen yang berlaku di PKS. Kriteria panen di lapangan tidak sama dengan kriteria panen di PKS karena jika disamakan yang terjadi adalah jumlah brondolan menjadi lebih banyak begitu juga buah over ripe. Kriteria di lapangan diberlakukan untuk lebih memudahkan pelaksanaan dan pemahaman pekerjaan potong buah oleh pemanen.

Jika pemanenan dilakukan dalam keadaan buah belum matang, selain kadar ALB rendah, rendemen minyak yang diperoleh juga rendah. 
Apabila pemanenan buah dilakukan dalam keadaan lewat matang, maka minyak yang dihasilkan mengandung ALB dalam persentase tinggi yaitu lebih dari 5\%. Berdasarkan hal tersebut di atas, ada beberapa tingkatan atau fraksi dari TBS yang dipanen. Fraksi-fraksi TBS tersebut sangat mempengaruhi mutu panen, termasuk kualitas minyak sawit yang dihasilkan (Fauzi et al., 2008). Tingkat kematangan tandan atau dikenal sebagai fraksi itu ditentukan berdasarkan kriteria jumlah buah lepas yang dapat dilihat pada Tabel 5.

Tabel 5. Hasil fraksi buah pemanen Blok C7 di kebun SBHE, pada tanggal 16 mei 2013

\begin{tabular}{clcc}
\hline No & $\begin{array}{c}\text { Tingkat } \\
\text { kematangan }\end{array}$ & Persentase (\%) & $\begin{array}{c}\text { Standar } \\
\text { kebun }(\%)\end{array}$ \\
\hline 1 & Mentah & 0 & 0 \\
2 & Kurang matang & 15.5 & $<8$ \\
3 & Matang & 77.2 & 85 \\
4 & Lewat matang & 6.5 & $<7$ \\
5 & Janjang kosong & 1 & 0 \\
\hline
\end{tabular}

\section{Grading buah adalah kegiatan} menggolongkan buah berdasarkan tingkat kematangan sesuai dengan standar yang telah ditentukan perusahaan, hasil grading akan dijadikan salah satu acuan untuk perbaikan mutu panen. Grading Buah (TBS) dilakukan minimal $10 \%$ dari total estimasi taksasi produksi pada hari pelaksanaan panen (Pedoman Teknis BGA). Persentase hasil pengamatan dapat diketahui dengan acuan BJR blok yang digunakan untuk menghitung jumlah brondolan dalam menentukan kriteria kematangan. Kriteria mentah ditunjukkan dengan tidak adanya brondolan yang terlepas pada TBS, kriteria kurang matang ditandai dengan adanya brondolan kurang dari 32 brondol untuk blok C8 dan 34 brondol untuk blok C7, kriteria matang ditunjukkan dengan adanya 32 brondolan untuk blok C7 dan 34 brondolan untuk blok C8 hingga $75 \%$ brondol permukaan lepas, lebih dari itu buah masuk kriteria lewat matang dan janjang kosong. Hasil pengamatan pada Blok C7 disajikan Tabel 5 dan Blok C8 pada Tabel 6.

Tabel 6. Hasil Fraksi Buah Pemanen Blok C8

\begin{tabular}{clcc}
\hline No & $\begin{array}{c}\text { Tingkat } \\
\text { kematangan }\end{array}$ & Persentase (\%) & $\begin{array}{c}\text { Standar } \\
\text { kebun }(\%)\end{array}$ \\
\hline 1 & Mentah & 0 & 0 \\
2 & Kurang matang & 12 & $<8$ \\
3 & Matang & 81.3 & 85 \\
4 & Lewat matang & 6.6 & $<7$ \\
5 & Janjang kosong & 0 & 0 \\
\hline
\end{tabular}

Hasil pengamatan di lapangan mutu buah padablok C7 dan C8 diketahui bahwa tidak ada buah yang dipanen mentah, $14 \%$ dipanen dengan kondisi kurang matang. Pemanen memotong buah kurang matang karena memotong buah < 5 brondolan yang jatuh alami di piringan. Jika di lapangan menyesuaikan dengan ketentuan di PKS maka brondolan akan menjadi banyak, karena pemanen akan menunda memotong buah yang layak potong hingga jumlah brondolan sesuai dengan banyaknya brondol yang harus lepas $\mathrm{Kg}^{-1}$ TBS.

Pendapatan pemanen yang dihitung berdasarkan banyak janjang yang dipanen dan pemenuhan basis janjang, juga menjadi penyebab pemanen cenderung memotong buah kurang matang untuk mencapai basis. Pemanen yang kurang paham tentang kriteria potong buah dengan ketentuan 5 brondolan jatuh alami di piringan, sering memanen buah kurang dari 5 brondolan yang jatuh di piringan. Kecenderungan pemanen memotong buah kurang matang dapat dicegah dengan memberi peringatan tiap hari mengenai ketentuan kriteria layak potong buah yaitu 5 brondolan yang jatuh alami di piringan.Peringatan disampaikan oleh mandor panen pada saat apel pagi dan apel sore dan penerapan denda dan sangsi secara konsisten.

Persentase tandan yang masuk kriteria matang $79 \%$ matang. Nilai persentase tandan yang matang belum memenuhi standar kriteria panen tandan yang ideal yaitu $85 \%$ (kriteria grading di PKS). Hal ini disebabkan karena masih tingginya pemanen yang memotong buah kurang matang.Kriteria lewat matang mencapai $6.5 \%$ lewat matang, nilai presentase ini masih di bawah batas maksimal kelonggaran lewat matang $<7 \%$ di PKS. Lewat matang dapat juga terjadi karena pusingan yangtinggi akibat seksi panen yang tidak selesai pada hari tersebut. Seksi panen bisa tidak selesai disebabkan angka kerapatan panen (AKP) tinggi dan tenaga kerja panen yang kurang. Selain itu, adanya pemanen yang kurang bertanggung jawab meninggalkan buah saat memanen buah, karena mereka telah memperkirakan buah yang dapat dipanen jumlahnya tidak akan mencapai basis janjang. Lewat matang yang disebabkan kurang bertanggung jawabnya pemanen pada hancanya, dapat diantisipasi dengan pemeriksaan hanca yang teliti oleh mandor panen terhadap pemanen yang outputnya tidak maksimal, dan menerapkan denda bagi pemanen yang mengeluarkan buah lewat matang yang terlalu banyak yaitu lebih dari $7 \%$ jumlah janjang yang dipanen di TPH kecuali janjang kosong karena terserang penyakit. Pemberlakuan denda ini dapat meningkatkan rasa tanggung jawab dari pemanen terhadap hancanya. 


\section{Kualitas Hancak Panen}

Kualitas yang harus dicapai oleh kebun dalam pemanenan terdiri atas mutu buah dan mutu hancak. Mutu buah yang dihasilkan dalam kegiatan pemotongan TBS akan berpengaruh terhadap kualitas minyak yang dihasilkan. Kehilangan produksi tercermin pada mutu hancak dalam pengecekan setelah pemanenan.Kualitas hancak panen menunjukkan kehilangan produksi dalam kegiatan pemanenan. Menurut Miranda (2009) penyebab terjadinya kehilangan produksi dapat dibagi dalam tiga kelompok, yakni faktor kondisi tanaman, faktor manusia, serta faktor lahan. Kegiatan pengecekan mutu hancak pemanen dilakukan oleh penulis setiap harinya dalam 7 hari dengan melakukan pemeriksaan terhadap lima pemanen. Sistem pemeriksaan hancak yang dilakukan oleh mandor adalah mengambil 100 pokok sampel setiap pemanen. Data pengamatan mutu hancak dapat dilihat pada Tabel 7.

Tabel 7. Hasil pengamatan mutu hancak di Divisi III Kebun SBHE

\begin{tabular}{ccccc}
\hline \multirow{2}{*}{ Pemanen } & \multicolumn{2}{c}{ Brondolan tinggal } & $\begin{array}{c}\text { Tandan } \\
\text { matang tidak } \\
\text { dipanen }\end{array}$ \\
\cline { 2 - 5 } & Piringan & Pelepah Gawangan & 0 \\
1 & 34 & 1.0 & 2.0 & 0 \\
2 & 26 & 2.0 & 0.0 & 0 \\
3 & 36 & 1.0 & 2.0 & 0 \\
4 & 29 & 3.0 & 0.0 & 0 \\
5 & 22 & 1.0 & 0.0 & 0 \\
\hline Rata-rata & 29.4 & 1.6 & 0.8 & 0 \\
\hline Brondolan & & 0.3 & & \\
pokok & & & & \\
\hline
\end{tabular}

Berdasarkan hasil pengamatan (Tabel 7) nilai brondolan tinggal yang tidak terkutip sebesar 0.3 brondolan pokok-1 dan tandan matang tidak dipanen sebesar 0\%. Hasil tersebut menunjukkan bahwa kualitas hancak panen pada Divisi III Kebun Sungai Bahaur untuk tandan matang tidak dipanen sudah tercapai sedangkan brondolan tinggal belum mencapai target maksimum, akan tetapi nilai brondolan tinggal tidak terkutip masih di bawah ketetapan pemanen untuk mendapatkan sanksi yaitu lebih dari 2 brondolan pokok ${ }^{-1}$. Target yang belum mencapai maksimum disebabkan oleh angka kerapatan panen yang tinggi sehingga pemanen lebih fokus pada penyelesaian hancak panen dan kurang ketelitian pemanen.

\section{KESIMPULAN}

Pelaksanaan magang sesuai dengan tujuan magang khususnya dalam aspek pemanenan.
Penulis dapat melakukan pengamatan meliputi perhitungan angka kerapatan panen, kebutuhan tenaga panen, kualitas pekerjaan panen, pelanggaran dan denda panen, kriteria panen dan mutu hanca panen. Hasil pengamatan menunjukkan manajemen pemanenan di kebun SBHE kurang baik. Hasil pengamatan menunjukkan jumlah tenaga kerja di lapangan lebih tinggi dari kebutuhan tenaga kerja panen. Kualitas pekerjaan panen masih di bawah standar kebun. Pemanen memotong buah kurang matang lebih tinggi dari toleransi standar kebun dan pemanen memotong buah matang lebih rendah yaitu $79 \%$ dari standar minimal kebun yaitu $85 \%$.

\section{DAFTAR PUSTAKA}

[BGA] Bumitama Gunajaya Agro. 2010. Pedoman Teknis Agronomis Kelapa Sawit (Elaeis guineensis Jacq.). Jakarta (ID): BGA Group Plantations.

[Ditjenbun] Direktorat Jenderal Perkebunan. 2014. Statistik Perkebunan Indonesia: 2012-2014 Kelapa Sawit. Jakarta (ID): Sekretariat Ditjen Perkebunan.

[PPKS] Pusat Penelitian Kelapa Sawit. 2007. Budi Daya Kelapa Sawit. Medan (ID): PPKS.

Fauzi, Y, Widyastuti, Y.E, Satyawibawa, I., Hartono, R. 2008. Kelapa Sawit : Budi daya Pemanfaatan Hasil dan Limbah Analisis Usaha dan Pemasaran. Jakarta (ID): Penebar Swadaya.

Jalaluddin, Toni, J. 2005. Pemanfaatan kaolin sebagai bahan baku pembuatan aluminium sulfat dengan metode absorps. Jurnal Sistem Teknik Industri. Vol.5.

Lubis, A.U. 2008. Kelapa Sawit (Elaeis guineensis Jacq.) di Indonesa. Medan (ID): Pusat Penelitian Kelapa Sawit.

Lubis, R.E, Widanarko, A. 2011. Buku Pintar Kelapa Sawit. Edisi 1. Jakarta (ID): Agomedia Pustaka.

Mangoensoekarjo, S., Semangun, H. 2005. Manajemen Agribisnis Kelapa Sawit. Yogyakarta (ID): Gadjah Mada University Press. 
Nurmalisa, M. 2011. Pengelolaan panen tanaman kelapa sawit (Elaeis guineensis Jacq.) di Sungai Bahaur Estate, PT Bumitama Gunajaya Agro, Kotawaringin Timur, Kalimantan Tengah [skripsi]. Bogor (ID): Institut Pertanian Bogor.

Pahan, I. 2013. Manajemen Agribisnis dari Hulu Hingga Hilir. Jakarta (ID): Penebar Swadaya.

Pardamean, M. 2008. Panduan Lengkap Pengelolahan Kebun dan Pabrik Kelapa Sawit.. Jakarta (ID): Penebar Swadaya.
Sastrosayono, S. 2005. Budi Daya Kelapa Sawit. Tangerang (ID): Agomedia Pustaka.

Setyamidjaja, D. 2006.Kelapa Sawit, Teknik Budi Daya, Panen, dan Pengolahan. Yogyakarta (ID): Kanisius.

Sunarko. 2010. Budi daya dan pengelolaan Kebun Kelapa Sawit dengan Sistem Kemitraan. Edisi II. Jakarta Selatan (ID): Agomedia Pustaka. 